\title{
Evaluation of the results of marketing management of retail structures' innovative development
}

\author{
Yulia Medvedeva ${ }^{1, *}$ \\ ${ }^{1}$ Don State Technical University, 344000, Rostov-on-Don, Russia
}

\begin{abstract}
Evaluation of the effectiveness of marketing management of retail structures' innovative development is necessary to measure the effectiveness of the enterprise and to evaluate strategic ways of business development. Both of these areas determine the competitiveness of retail structures (RS). The article substantiates the approach to the effectiveness of marketing management of retail structures' innovative development based on the compliance of development plans, organizational systems and structures with the strategic goal of innovative development, as well as the possibility of achieving the goals of innovative development strategies at various planning horizons, monitoring and adjusting adopted and/or implemented innovative development plans. Evaluation of the effectiveness of marketing management of retail structures' innovative development is based on a comprehensive approach to the results of RS development. The paper offers an original approach to evaluating the effectiveness and efficiency of marketing management of RS innovative development, which allows you to identify the relationships between the components of the model to determine how the resources involved in marketing management processes generate an impact. The main directions of evaluating the effectiveness of marketing management of retail structures' innovative development are determined through the effect received by the commodity circulation participants.
\end{abstract}

\section{Introduction}

There is no single approach to the evaluation of marketing efficiency and performance. Several of the most relevant publications address complex issues of defining and measuring marketing performance (e. g., [1-3]), while others discuss the financial return and ROI of marketing investments $[4,5]$.

Within the framework of this study, the interest is not the efficiency of departments nor the productivity of specific marketing activities (e. g., promotion), but the general achievements of the company in the field of marketing. Particular issues of marketing performance depend on what specific goals have been set. They differ from company to company; while the need to generate net cash flow through customer satisfaction is universal, even for non-profit organizations.

\footnotetext{
*Corresponding author: jjmedvet@yandex.ru
} 
J. Sheth and R. Sisodia, discussing effective marketing decisions, distinguish between such concepts as effectiveness and efficiency [6]. According to this approach, effective marketing is determined in relation to two criteria: customer satisfaction (effectiveness) and marketing costs (efficiency).

In the context of marketing management of innovative development, it is advisable to rely on the approach proposed by $\mathrm{O}$. K. Oiner, which defines performance as a combination of the degree of efficiency and effectiveness of the implementation of planned activities and achievement of planned results [7].

Ya. S. Matkovskaya proves that innovative activity and marketing of innovative technologies bring not only a commercial impact, but also a number of other external positive impacts, many of which are difficult to measure. The author shares the position of Ya. S. Matkovskaya that it is important to conduct research and find ways to measure the multidimensional impacts of marketing management [8]. We consider it expedient, when conducting an evaluation, to adjust the effectiveness of marketing components with innovation and financial results obtained as an outcome of marketing management of RS innovative development. It is necessary to take into account that the impact of innovation activity is diverse and affects the key areas of RS functioning [9]. So innovative activity is reflected in the following types of impact:

- marketing impact, which evaluates market changes as a result of the introduction of innovations;

- economic impact, which is the ratio of the results of the implementation of innovations and the costs of achieving them;

- financial impact, which evaluates financial results obtained after the introduction of innovations;

- scientific and technical impact, which is based on the introduction of new technical and technological solutions;

- resource impact, which tracks changes in consumption and distribution of resources as a result of the introduction of innovations;

- ecological impact, which evaluates changes of the environment [10];

- social impact, which is the influence of innovation on socially significant factors.

Evaluation of the effectiveness of marketing management of RS innovative development is based on an integrated approach to the results of the RS development. RS managers, majority and minority shareholders as well as counterparties are interested in the results of RS development (to assess their risks, including financial ones).

Within the framework of the concept of marketing management of innovative development, the interest is not the efficiency of the departments nor the productivity of specific marketing activities (e.g., promotion or merchandising), but the general achievements of RS development and innovative development. The effectiveness of marketing management of RS innovative development, thus, is determined through the evaluation of the contribution to the final outcomes of marketing, financial and innovative results and their optimal balancing. Another limitation in calculating the marketing effectiveness of management, in its pure form, is the impossibility of separating marketing costs from management costs.

\section{Materials and methods}

The research is based on the application of the method of descriptive and analytical comparison, the method of semantic and structural analysis, the method of monitoring the content of terminology in theoretical and applied research papers within the chosen field of study. To monitor the dynamic development of retail structures, as well as the transformation of the role of the concept of marketing management in innovative 
development, this article uses a research case study as a methodology. Company data are taken from annual financial statements and open sources of information.

Evaluating the contribution of marketing to company performance in this broad sense has become an important issue, but the views of researchers are polarized. Some scientists argue that the ultimate goal of marketing is to increase shareholder value and that therefore the effectiveness of marketing should be assessed by a single financial indicator, which T. Ambler called the "silver metric" [4]. If shareholder value is not feasible on its own because it mixes with too many other factors, then discounted cash flow (DCF) or return on marketing investment (ROMI or ROI) should be used.

One of the approaches to evaluating the effectiveness of marketing management is based on the analysis of marketing costs. Metrics such as return on marketing investment (ROMI - Return On Marketing Investment and ROI - Return On Investment) and return on marketing objectives (ROMO) are examples of marketing performance metrics used by large companies to prioritize and allocate marketing investments.

Although the importance of ROI and the unconditional usefulness of the indicator for estimating investment alternatives are highly evaluated, this methodology is criticized by some marketers as it was developed to compare capital projects in which investments are made once, and profitability is gained in subsequent years. The main objection to ROI or ROMI is that marketing spending is not an investment in the original sense and, therefore, is not included into the company's books. For capital projects, since cash flows can be deferred for several years, costs are usually attributed to a specific period of time. While marketing expenses can affect later periods, they tend to only target the current year. All this is reflected in the profit and loss account, and not on the balance sheet. From this point of view, marketing is an additional tool that can be used if ROI for these additional profits is high enough.

The second approach to evaluating the effectiveness of marketing management is associated with discounting cash flows, which is used as a basic methodology for a number of different metrics: net present value (NPV), brand valuation [11], customer lifetime value (CLV) [2, 12], client equity [13], and, typically, brand valuation [4]. Planning involves comparing alternative future scenarios; comparing their expected results in terms of future cash flows is completely logical and was their original rationale. So, in the context of unstable market changes, the most reliable marketing result of RS development is loyal suppliers and consumers $[14,15]$. Therefore, it is proposed to use indicators of consumer retention, the percentage of those involved in the creation of innovations, and the Net Promoter Score (NPS) measuring consumer loyalty as indicators of consumer evaluation of the effectiveness of marketing management of RS innovative development.

\section{Results and Discussion}

The stakeholders in the process of organizing retail trade are the trade enterprise itself, consumers, manufacturers and society as a whole [16]. Evaluation of the effectiveness of marketing management is part of the marketing model of marketing management of innovative development; it serves as both the starting point of marketing management and an indicator of its effectiveness.

The proposed approach to evaluating the effectiveness and efficiency of marketing management of RS innovative development identifies relationships between the components of the model in order to explore how the resources involved in marketing management processes generate an impact. The presented approach determines the following stages of assessing financial performance indicators of marketing management of RS innovative development. 
1. Development of a mechanism for generating the impact of marketing management of RS innovative development through the description of drivers and/or leading indicators (Fig. 1).

2. Identification of relationships between the evaluation components to determine how investments in marketing management of RS innovative development generate financial returns.

3. Definition of metrics for planning and monitoring the performance of each component of the model.

4. Determination of the marketing management profitability by comparing the increase in the cost of marketing, innovation and financial results as well as the profit of RS with the costs of this management.

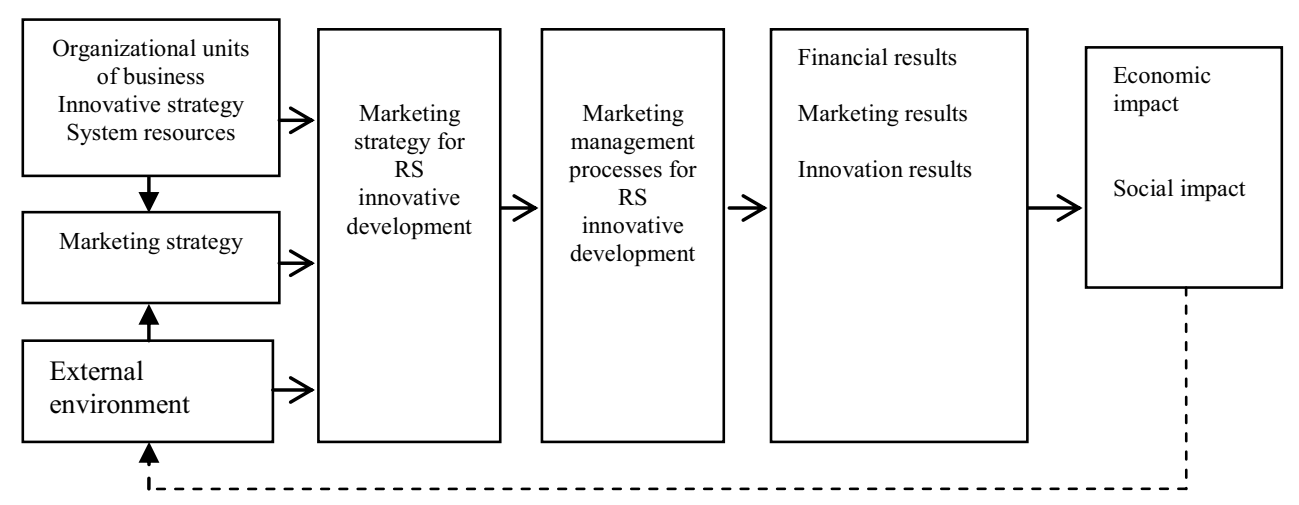

Fig. 1. A systematic approach to the formation of the impact of marketing management of RS innovative development: prerequisites and outcomes.

In this study, the concept of marketing results is based on the resource approach. Marketing result is determined by the totality of material or non-material resources, the use of which is capable of generating additional value for consumers and additional income for RS due to the interaction of the enterprise with the market environment. Marketing results include the following: company name and reputation (brand assets) and customer capital (customer base), which creates foot traffic and partnerships. Marketing results increase shareholder value by increasing the volume and speeding up cash flow and by reducing the volatility of the company's operations and their risk, etc.

Innovative results in RS development are considered to be tangible and intangible outcomes of RS innovative development, which make it possible to form an income stream through the implementation of innovative projects that increase the competitiveness and value of trade services in the current or future periods [17, 18].

Basing on the methodological support of marketing management of RS innovative development, we define the following requirements for the evaluation system to assess the effectiveness of marketing management of RS innovative development:

- ability to evaluate the impact on the efficiency of RS business processes;

- ability to evaluate the overall level of implementation of marketing management in the RS business model;

- element-wise approach to evaluating the components of the effectiveness of the marketing mix of RS innovative development;

- ability to evaluate external impacts obtained from RS innovative development by the consumer, manufacturer and society as a whole;

- measuring marketing results from a consumer perspective. 
The main directions for evaluating the effectiveness of marketing management of RS innovative development are determined through the impact obtained by commodity circulation participants (RS, consumer, manufacturer, society as a whole).

Thus, marketing management aimed at innovative development must be evaluated taking into account the costs of innovation and the impact of marketing metrics on the financial result of the RS functioning.

The effectiveness of marketing management of RS innovative development can be represented as a function with three variables which are indicators of the effectiveness of innovative, marketing and financial activities:

$$
\mathrm{EMM}=[\Delta \mathrm{f}(\mathrm{U} 1, \mathrm{U} 2, \mathrm{U} 3)]:(\Sigma \mathrm{R}),
$$

where:

$\mathrm{f}(\mathrm{U} 1, \mathrm{U} 2, \mathrm{U} 3)$ - function that characterizes the state of the RS system;

Ui $(i, 1, \ldots, n)$ - values of the system indicators reflecting individual indicators of marketing management of innovative development;

$\Sigma \mathrm{R}$ - total amount of resources spent.

An additive model for evaluating the effectiveness of marketing management of RS innovative development can be represented as follows:

$\mathrm{EMM}=\Sigma \mathrm{Mr}+\Sigma \mathrm{Fr}+\Sigma \mathrm{Ir}$,

where:

$\Sigma \mathrm{Mr}$ marketing results

$\Sigma \mathrm{Fr} \quad$ financial results

$\Sigma \mathrm{Ir} \quad$ innovation results

It should be noted that specific indicators included in the financial, innovation or marketing block are selected by each enterprise based on the goals of marketing management of RS innovative development. To evaluate each group of indicators, it is necessary to assign a weight to each indicator according to the degree of influence on the effectiveness of marketing management. The indicators proposed by the company's management must be compared with the benchmark indicators (they can be planned values or industry averages, benchmarking values).

Table 1. Integral evaluation of the components of the effectiveness of marketing management.

\begin{tabular}{|c|c|c|c|c|c|}
\hline $\begin{array}{l}\text { Group of } \\
\text { factors }\end{array}$ & Indicators & Point score $q_{i}$ & Weight $w_{i}$ & $\begin{array}{c}\text { Weighted } \\
\text { estimate } Q_{i} \\
Q_{i=} q_{i} * w_{i}\end{array}$ & $\begin{array}{c}\text { Integral asset } \\
\text { valuation }\end{array}$ \\
\hline \multirow{3}{*}{$\begin{array}{l}\text { Marketing } \\
\text { results }\end{array}$} & $\mathrm{U}_{\mathrm{m} 1}$ & $q_{m l}$ & $w_{m 1}$ & $Q_{m l}$ & \multirow{3}{*}{$\Sigma \mathrm{Mr}=\Sigma \mathrm{Q}_{i}$} \\
\hline & $\mathrm{U}_{\mathrm{m} 2}$ & $q_{m 2}$ & $w_{m 2}$ & $Q_{m 2}$ & \\
\hline & $\mathrm{U}_{\mathrm{mn}}$ & $q_{m n}$ & $w_{m n}$ & $Q_{m n}$ & \\
\hline \multirow{3}{*}{$\begin{array}{l}\text { Financial } \\
\text { results }\end{array}$} & $\mathrm{U}_{\mathrm{fl}}$ & $q_{f 1}$ & $w_{f 1}$ & $Q_{f 1}$ & \multirow{3}{*}{$\Sigma \mathrm{Fr}=\Sigma \mathrm{Q}_{i}$} \\
\hline & $\mathrm{U}_{\mathrm{f} 2}$ & $q_{f 2}$ & $w_{f 2}$ & $Q_{f 2}$ & \\
\hline & $\mathrm{U}_{\mathrm{fn}}$ & $q_{f n}$ & $w_{f n}$ & $Q_{f n}$ & \\
\hline \multirow{3}{*}{$\begin{array}{l}\text { Innovation } \\
\text { results }\end{array}$} & $\mathrm{U}_{\mathrm{i} 1}$ & $q_{\mathrm{i} 1}$ & $w_{\mathrm{i} 1}$ & $Q_{\mathrm{i} 1}$ & \multirow{3}{*}{$\Sigma \operatorname{Ir}=\Sigma Q_{i}$} \\
\hline & $\mathrm{U}_{\mathrm{i} 2}$ & $q_{\mathrm{i} 2}$ & $w_{\mathrm{i} 2}$ & $Q_{\mathrm{i} 2}$ & \\
\hline & $\mathrm{U}_{\text {in }}$ & $q_{\text {in }}$ & $w_{\text {in }}$ & $Q_{\text {in }}$ & \\
\hline EMM & & \multicolumn{4}{|c|}{$\Sigma \mathrm{Mr}+\Sigma \mathrm{Fr}+\Sigma \mathrm{Ir}$} \\
\hline
\end{tabular}

In order to realize the possibility of using the integral indicator of the effectiveness of marketing management of RS innovative development, it is necessary to interpret the values of the indicator for each group of results and the general one. To do this, its maximum and minimum values are to be calculated. The maximum value will be reached if each grade on the point scale is 5 ; the minimum value will be reached if the grade is 1 . 
It is not possible to establish the standard value of the integral indicator, since the number of indicators in the evaluation of individual RS will differ. The number of estimates multiplied by five points will correspond to the maximum value for the indicator, the sum of the maximum weighted average estimates will correspond to the reference value of the indicator for enterprises.

\section{Conclusion}

The effectiveness of marketing management of retail structures' innovative development is a multidimensional concept which stems from the impact of innovation and marketing management, and takes into account the financial results obtained.

The key entity interested in the effectiveness of development is the RS management. The effectiveness of marketing management of RS innovative development determines the market value of a company, as it is aimed at achieving long-term results and ensures the investment attractiveness of large RS. So, after the new development strategy presentation, shares of PJSC Magnit fell in value by more than 50 percent (from 10,600 rubles in September 2017 to 3,000-4,000 rubles in 2019) [19]. At the same time, the main competitor, X5 Retail Group, systematically caught up with Magnit in terms of capitalization, and in 2019 became the industry leader in Russia in all respects.

Magnit, the largest RS in the Russian retail market, has successfully used an intensive development strategy based on multi-format (offline) regional expansion with a small share of placement in the Central Federal District, without introducing elements of innovative development and qualitative growth into its activities. Thus, the company started design renewal and store reconstruction, both of which are one of the trends in the retail sector, later than the main competitor, and the pace of renovations carried out did not match that of its competitors. The reconstruction of Pyaterochka stores, owned by X5 Retail Group, was actually completed by the end of 2017; the renovation of Perekrestok (owned by X5 Retail Group as well) started in 2019 and is also coming to an end. Currently, Magnit has updated just over $50 \%$ of its proximity stores and $20 \%$ of supermarkets. At the same time, according to Magnit, store renovations are driving LFL numbers up for proximity stores by $30 \%$ compared to the pre-renovation data. Until 2019, Magnit did not have a loyalty program, which also negatively affected the retailer's competitiveness.

The identified strategic omissions of Magnit led to a decrease in key operating performance indicators, while the indicators of the main competitor were growing.

The trigger for the decline in the company's market value was Magnit's Development Strategy. The strategy determines that consumer behaviour has changed, and the share of consumers using digital technologies is growing. It is noted that the Russian e-commerce market remains very fragmented compared to the largest foreign markets, and the share of FMCG goods has a huge growth potential. However, Magnit's innovation and marketing activities are extremely limited. The absence of a real action program aimed at innovative development led to the fact that, given all the voiced opportunities of the RS market, the market reacted by lowering prices for the company's shares.

Thus, Magnit was unable to provide the market with timely marketing solutions in the field of innovative development. Personalization was not performed in 2018, and the strategy proposes the introduction of a cross-format loyalty program and a bonus program. Informatization as the basis for the innovative development of the RS industry is not considered (there are no plans for the development of the e-commerce sector). Transformation of trade formats can be considered a positive factor in Magnit RS innovative development.

It can be summarized that the effectiveness of innovative development in the retail sector can be evaluated not so much using indicators of the effectiveness of innovative 
activities (e. g., innovative activity, share of costs for innovative development, number of innovations adopted for implementation), but also using marketing indicators that are reflected in the overall performance of company management and its competitive position.

\section{References}

1. N.A. Morgan, B.H. Clark, R. Gooner, J. Bus. Research 55(5), 363-75 (2002)

2. S. Gupta, D.R. Lehmann, Managing Customers as Investments (2005)

3. D.R. Lehmann, D.J. Reibstein, Marketing Metrics and Financial Performance (2006)

4. T. Ambler, F. Kokkinaki, S. Puntoni, J. Market. Man. 20(3-4), 475-498 (2004)

5. J. D. Lenskold, Marketing ROI (2003)

6. J. Sheth, R. Sisodia, J. Bus. Research 55(5), 349-362 (2002)

7. O. K. Oiner, Marketing Performace Management (2016)

8. Ya. S. Matkovskaya, Fin. and Cred. 24(408) (2010)

9. I. Krasyuk, M. Yanenko, E. Nazarova, E3S Web Conf. 164, 09006 (2020)

10. O. E. Pirogova, TTPS 4(30) (2014)

11. R. Perrier, Brand Valuation (1997)

12. R. Venkatesan, V. Kumar, J. Market. 68(4), 106-25 (2004)

13. R.T. Rust, K.N. Lemon, V.A. Zeithaml, J. Market. 68(1), 109-27 (2004)

14. I.A. Krasyuk, V.V. Bakharev, Y.Y. Medvedeva, ICIE-2017, SHS Web Conf. 35, 01052 (2017)

15. O. Pirogova, M. Makarevich, O. Ilina, V. Ulanov, IOP Conf. Ser.: Mater. Sci. and Eng., 012129 (2019)

16. I. Kapustina, T. Pereverzeva, T. Stepanova, I. Rusu, IOP Conf. Ser.: Mater. Sci. and Eng., 012120 (2019)

17. S. Bozhuk, N. Krasnostavskaia, T. Maslova, N. Pletneva, IOP Conf. Ser.: Mater. Sci. and Eng. (2019)

18. S. Krymov, M. Kolgan, S. Suvorova, O. Martynenko, IOP Conf. Ser.: Mater. Sci. and Eng. (2019)

19. Prices for Magnit's shares continued falling after publishing its Sustainability Strategy (2018)

20. Yearly financial report of X5 Retail Group (2019)

21. Magnit's Development Strategy (2018) 